\title{
Images of Learning through Music: The Sounds of Cognition
}

\section{Laura Ritchie,}

\author{
University of Chichester, United Kingdom
}

\begin{abstract}
This innovative practice uses classical string instruments as the tools, and music as the medium for exploring learning new and complex tasks. In a face-to-face setting people experience playing violins, violas, and cellos as their learning is guided by visual and aural imagery, enabling engagement with complex cognitive and affective concepts through what appears to be play. By accessing concept knowledge directly through representation and then experience, the need for translation of technical or theoretical material is bypassed. The progressive introduction of mental and physical skills actively illustrates the cumulative impact of the cognitive, the coordination, and the interactive demands of playing the instruments. Active reflection in and on the experience of playing a musical instrument, working collaboratively, and allowing and enjoying public learning (and failure) is contextualised in terms of people's selfefficacy beliefs, their attitudes toward learning and skill development, and the relevant transferability of these realised and learned ideas to their personal work and life situations.
\end{abstract}

Keywords: Experiential Learning, Self-Efficacy, Metacognition, Reflection, Imagery

Received: 21 July 2020

ISSN 2056-757X

Revised: 8 Aug 2020

Accepted: 30 Aug 2020

https://doi.org/10.18646/2056.73.20-018 


\section{Introduction}

Using music as a metaphor, this innovative practice works with sound, image, and the tactile experience of first playing a physical instrument to allow learning, discovery, and complex reflection through play. Metaphorically, this lived experience of learning spins the plates of a person's attention, perception of self and situation, and their intention, while weighing them with their sense of self-efficacy as they develop agency. It invites people's internal capacity for vision to feed their motivational and learning appetites. Self-efficacy beliefs focus on an individual's capability to carry out a specific task (Bandura, 1977), and developing these beliefs can lead to resilient, selfdirected, confident achievement (Zimmerman, 2000; Ritchie, 2015). Importantly, Cervone (2000) reminds us that "self-efficacy should not be thought of as a static entity that people 'have' but as a dynamic cognitive process that people 'do"' (p.32).

Developing metacognition and the awareness of skills' component processes contribute to competent self-directed learning (Miksza, 2012; Bembenutty, Kitsantas, and Cleary, 2013), and this helps people adopt aspects of heutagogy, where there is a constant analysis and reflection on learning (Blaschke, 2012). The internal vision of the mind does not flow in typed characters of textbooks. When new material is presented to be learned through words, there are always layers of internal translation and abstraction that precede the apprehension of meaning. Using music as a medium to address core processes, skills, and beliefs bypasses these transitory stages to directly experience concepts.

Within education the notion of using external objects to aid learning through representative or fun means like games, and specifically 'serious games' allow for experiences that are enjoyable but also include learning as a by product (Shreve, 2005; Winn, 2009). However, sometimes learning content is superimposed on educationally framed games, especially when the framework is borrowed from an existing external game, for example when a quiz or trivia game is adapted for an educational theme (Halverson, 2005).

LEGO® is used in Serious Play (Roos and Victor 2018) and the nature of the colourful plastic pieces, with their simple shapes and infinite building possibilities, allow creative expressions through construction that can either directly or metaphorically represent things or ideas. Nerantzi and James (2019) highlight that even after a few minutes a person unfamiliar with LEGO ${ }^{\circledR}$ can successfully build, and they suggest its simplicity and versatility contribute to its success (see also James and Nerantzi, 2018). Serious Play involves a combination of constructive play and discussion with others, allowing people to engage creatively with solving complex problems, and it has been adopted in both education and corporate settings (James, 2013). They do raise the question of whether other materials could be used instead of these plastic bricks, and list alternatives ranging from inanimate, basic objects such as pebbles or sticks to other traditional children's toys like play dough and crafting supplies.

\section{Playing with instruments}

The innovative practice presented here uses classical orchestral instruments, which are neither toys nor something anyone would be given and expected to know how to 'play'

International Journal of Management and Applied Research, 2020, Vol. 7, No. 3 
it. Violins, violas, and cellos are tools used by professionals. This practical experience is still playful, but unlike with LEGO ${ }^{\circledR}$, where people create what they imagine, here they begin without any preconceived vision of outcomes or expectation of needing to be competent or for instigating or directing the learning at all. These participants are genuinely in a position to be led in a new experience, in an open and full way. In a comparable setting to a trust game where one partner leads the other, who is blindfolded, except in this setting everyone has their eyes and ears open and is fully in charge of their own actions and reactions.

Imagine a room full of classical string instruments, set out as an orchestra, waiting for non-musicians to enter and experience these for the first time. This is not about musical learning; music is used as a medium for exploring and experiencing interpersonal dynamics, personal capabilities, real-time problem solving, public failure, and both collaborative and individual success. During this innovative approach to play and teaching, people experience and reflect on their cognitive and physical processes, and the impact of these on their perceived self-efficacy in both this setting and in their daily and professional lives. Through this new experience and the subsequent reflection, they unpack layers of cognition, metacognition, underlying processes, and transferable skills.

The theoretical underpinning for this musically-based session borrows from the Mechanics, Dynamics, and Aesthetics (MDA) framework in Serious Gaming (Hunicke, LeBlanc, and Zubek, 2004) where specific processes, mechanics and rules, are communicated and understood before engagement can take place. Dynamics include the real-time engagement, inter- and intrapersonal interaction, and the collaborative nature of sound creation in music. Aesthetically, people are not competitive in terms of the traditional concept of winning, yet they are aware of personal challenge and of (often unexpected) accomplishment with music. The player follows some programme or protocol as they playing the instruments, and this allows the delivery and experience of cognitive, physical skill-based, and affectively learning outcomes, which parallel learning outcomes in games as classified by Kraiger, Ford, and Salas (1993). Interestingly, Hunicke, LeBlanc, and Zubec (2004) state engagement with entertainment, such as music or film, is unpredictable and not structured in this way, however although musical learning allows freedom, at the outset there is a distinct progression that does resemble 'the rules of the game'. It is through establishing and understanding these rules that one can then navigate them to experiment and have fun.

The mechanics of music are presented through related metaphor, using everyday images. For example drawing upon everyday tasks where physical positioning and muscle use is similar. Imagery is used to engage with the mind's eye to project goals before the physical motions are attempted, allowing people to be prepared successfully for their first engagement. Carefully described iterative steps that allow people to feel capable of otherwise complex processes. Everyone understands the familiar feeling of holding a water bottle, with the hand in a rounded ' $C$ ' shape is also that of the cellist's left hand. The left hand fingers on the strings are then likened to a child hanging on a climbing frame, where arm weight holds the strings down instead of using muscles to press from above. These familiar images convey known, non-threatening experiences.

International Journal of Management and Applied Research, 2020, Vol. 7, No. 3 
A starting point of competency removes feelings of anxiety, vulnerability, dissolves the fear of failure, and encourages a calm body and open mind. All of these are necessary for the next step in learning which challenges people to think differently by using an unexpected part of the body - the ear.

In dual coding theory Clark and Parvio (1991) note the associations between words and deeper processes and concepts, and likewise Roberts (2017) stresses the role of images to "organically stimulate active learning". The acknowledgement of differences in how experience relates to different modes of engagement is nothing new; William James (1912) believed that "there is only one primal stuff or material in the world... and we call that stuff "pure experience"' (p.4). He went on to illustrate the distinction between the nature of experiencing via thought or things named in terms of words: "As thing, the experience is extended; as thought, it occupies no space or place. As thing, it is red, hard, and heavy; but who ever heard of a red, hard or heavy thought." (pp. 2728). There are inherent problems with words. Wittgenstein (1967) also demonstrates how words are reliant on concrete understanding: "Colour-words are taught like this: 'That's red', e.g.- Our language-game only works, of course, when a certain agreement prevails" (para. 430), and this is relevant here because the subjective experience is by nature individual and not a matter of agreement.

I propose that sound can bypass the need for specific words to be directly associated with or to defining experience, and it can also instigate imagination and symbolic representation and link to cognitive and affective processes. In the innovation described below, I do use words to address mechanics, but the use of words is not about their associative, implied, or understood meaning but about their auditive qualities. Here gesture, non-verbal communication, images, and sound itself take shape and become a communicative and expressive tool.

\section{This Innovative Practice: Experiencing through Sound}

The following description of the innovative practice is presented both as a theoretical explanation and quoted extracts from a session I delivered in January 2017 as part of the Postgraduate Certificate of Learning and Teaching at the University of Chichester.

\subsection{Session overview and introduction:}

The session begins as people enter the room and their first experience is to confront an instrument at their chair. They progress through the mechanics of playing the instrument, beginning with holding the instrument, to making sound on the open strings by plucking (using the fingers) and then with the bow, and finally to adding different pitches by using individual fingers to hold down the strings. Interactively they first have to figure out how to play together, identifying non-verbal listening and physical cues to maintain a cohesion. Then the dynamics of a group are explored as individuals contribute to a whole, as an orchestra playing different parts that fit to create a larger aesthetic picture.

"Welcome - Please take a seat in the front of the room next to an instrument. What we're going to do is use music as a medium and a metaphor for how you learn. We are indeed going to play these instruments; and part of the magic of that it is called 'play' and not

International Journal of Management and Applied Research, 2020, Vol. 7, No. 3 
'work'. I do not intend to turn any of you into classical musicians. What I hope to show you through experiential learning is how you think about yourself and approach tasks makes a difference."

With any new thing, there are a range of skills required and the interesting thing with music is there are layers of increasingly cognitive and physical skills required. To introduce the instruments themselves, words are not used. Instead I tell a story about a childhood experience while carefully getting out my cello, modelling and demonstrating the correct behaviour through a lived image, and without words. In selfefficacy theory, observed experiences, especially where the model is considered similar to yourself, influence judgements of capabilities (Schunk, 1989).

"When I was 12 my uncle decided to take me water skiing and I said I was a bit scared. He said it's fun, it will be fine! He obviously did not think about how he was teaching me or what impact it would have on me, but now I am quite fearful of water things and it takes me a long time to be comfortable with new experiences. The way we approach and lead others to new experiences can make a huge impact on their learning, achievement, and future success. Today I will give you the inside commentary to everything I do.

Did you notice what you just witnessed alongside my story? You all watched me take out my own cello and get ready to play. First you saw the instrument as you came in the room, and now you have seen someone get ready to play the instrument. All of our experiences in life start with what we know, but since you have just seen me engage with the instrument, you now have information on which to base your judgement of what you can do."

\subsection{Tactile learning through associated images and experience:}

A visual preface is given in a parable-like format, with a story and demonstration before people physically meet their instruments.

"A cello is a very big thing, and that is interesting because in everyday interactions we have great respect for one another in terms of personal space and boundaries, and certainly for our students, they come to us and we are aware that they are each their own individual universe, and they may or may not have experience of the (meta)cognitive skills we present or require in new learning. Likewise, it would be very unusual not to acknowledge the need for physical space by walking up to someone and getting very close to their face. The reason I say that is because these instruments are big, and they are going to get close to you, and even more strange is going to be when we make the first sound because we also physically feel the sound with the instruments."

Even though there is difficulty in the layered complexity of tasks there are ways of introducing skills progressively so people are not solely allocating their conscious

International Journal of Management and Applied Research, 2020, Vol. 7, No. 3 
effort to that skill. If all the components are presented at the outset, fear and the unknown can overwhelm, acting as barriers to understanding.

The rationale behind the stepwise adding of skills allows people to experience an awareness of both progressive loading of cognitive skills and increased demands of physical coordination of playing the instruments (see Parry, 2004). Although in learning and work, mental and physical overload can result in injury (Mehta and Agnew, 2012), in this workshop situation the players' sounds illustrated the principle of overload without risk of actual damage. Interestingly, in the session there is great evidence of failure (aurally) as plucks become sproings and bowed notes squawk and grunt, yet the room is filled with laughter and more sound. This is atypical of what is commonly displayed in learners; learners tend to fear failure, have low self-efficacy, and avoid engagement (Caraway, Tucker, Reinke, and Hall, 2003). They actively enjoy the failure, despite it being directly attributable to them in a noisy public way.

Learning progresses from simply finding the physical coordination to pluck the open strings to adding rhythm and then to individually improvising a rhythm and passing it to another player. People listen and watch. There are no words, and the story or sentiment created by the previous person is embraced and developed by the next. This improvisation is also a first public solo: the public forming and sharing of ideas is not a risk that would be taken in normal class or work situations. To access rhythms, the acoustic properties of words are used to bypass a need to understand music theory or notation. This is directly related to the direct access allowed when a word takes on a visual representation in dual processing theory (Snowling and Hulme, 2005). For example, this (subtly encouraging) sentence is said with stresses on the bold text: 'I can play-vi-o-lin' to communicate the intended rhythmic shape of the music.

Next, adding the bow opens a whole new dimension of sound and of conceptual demands. The right hand holds the end of the bow, but the physical point where the bow contacts the string is somewhere along the stick and not near the hand, thus the mind needs to work in abstraction to imagine the sound yet move and direct the hand somewhere different in space from where the sound happens. This added task significantly increases both the mental and physical load.

Left hand fingers are added to introduce fine motor skills. This is added entirely through images. The $\mathrm{C}$ shape of the left hand holds a water bottle, the fingers hover over the strings like butterflies waiting to land, and when the fingers are down and need to lift, they unfurl like peeling a banana. None of these are musical or instrument specific images, but they all communicate the intricate motions needed in a simplistic, familiar and multi-modal way (Jewitt, Bezemer, and O'Halloran, 2016). What results by combining these images in a certain sequence is the nursery rhyme tune for 'Twinkle Twinkle Little Star', and upon realising what they are playing, smiles spread across faces and there are often audible gasps of delight.

\subsection{Reflective understanding:}

The session can continue for an hour, half a day, or a full day with explorations of groups as part of a whole and the dynamics of timing and balance, creating chords and painting sonic pictures, and communicating with sound. Regardless of the session

International Journal of Management and Applied Research, 2020, Vol. 7, No. 3 
length the plenary discussion includes revisiting the building blocks of rhythm and at that point they are introduced to the comparison of this approach to a word-based (or in this case musical notation based) technical approach. The rhythm sentences are presented visually, alongside the score notation for the same material covered, which takes a full page of music (see Figure 1 for extracts of the violin and cello sheet music scores.) It becomes evident how starting with this artefact would have needed layers of translation whereas using associative metaphor, visual imagery, and physically observed modelling drawing on the known prevented bombardment that would have occurred with attempting to read the musical 'text'. Instead of moving from artefact to image, as is typical in music learning (Swanwick, 1999) they began with the aural image.

\section{Figure 1: Examples of sheet music notation with associative phonetic text}
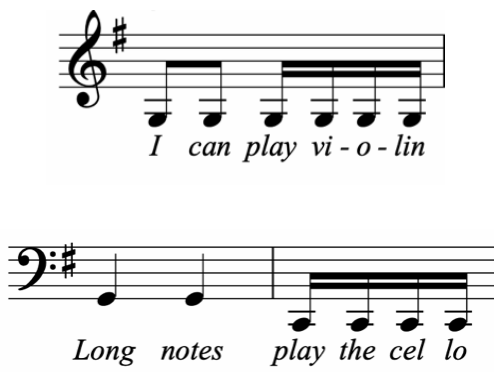

Finally, there is then a discussion of the underlying principles: how they approached this new and daunting task, was there fear, why were they confident, did they mind failing, how did they 'play' with others, and how these relate to other areas of their lives. Assumed barriers to engagement in daily life are unpicked and they are challenged to use this experience to genuinely challenge their habits.

\section{Evaluation and Discussion}

Using the tools of music allows an unexpected window into communication, skills, collaboration, and failure. Non-verbal interpersonal skills are experienced alongside real-time failure (and success) as people learn in public. In collaboration, people experience and embrace negotiating complex physical and mental processes, integrating them quickly and efficiently into practice by non-verbal cues. They deal with pressure (of a peer audience) and delivering results. One of the most effective aspects of this practice is that people cannot refute the fact that they have accomplished these things. It is not a conceptual or theoretical discussion or learning experience, and so there is added meaning in the experience.

Although the participant is led thorough the musical skills, the external directions are merely the LEGO® pieces for the participant to use as they build their own experience. They retain ownership of the process, especially as the focus is not on the actual music but the other processes of thinking, control, coordination, interaction with others, observation, and sense of self.

International Journal of Management and Applied Research, 2020, Vol. 7, No. 3 
Overwhelmingly, a by product of this experience is that people have a renewed sense of 'can do' in their outlook. Instead of learning about processes in a second-hand, translated way, through text, they experience them first hand, and the palpable outcomes 'playing' instruments and working with each other are irrefutable. When reflecting and questioning, the mechanics of the underlying skills and contexts are unpacked. For example how were they able to so successfully work as a mixed group of students, executives, senior staff, and groundskeepers with an unhampered, unified purpose? The non-existence of typically assumed boundaries allows for capabilities to be realised and self-efficacy to be judged and acted upon, allowing real growth.

This innovation has been carefully crafted to capitalise on the perceived uniqueness of playing a musical instrument. Yes, high levels of skill are required to obtain a professional standard but engaging on a basic level can be achieved through careful communication of a few fundamentals. Does this only work with music? No. But it does rely on a setting where the outcome is perceived as sufficiently specialised that most people would not consider it within their ordinary repertoire or skills. Various culinary settings would also work where there is indeed a high level of understanding and skill required to be a chef, but with carefully selected dishes the skills can be communicated to and successfully experienced by novices. The individual component skills and procedures may be fairly simple, but the results of the out come are surprising. If the outcome was named as the initial goal by asking someone to make profiteroles from scratch or to play Twinkle Twinkle, they would be likely to say no unless they already had experience.

Here, through association and the direct access to concepts through imagery, people do engage. Throughout dozens of such workshops I have not had a single person refuse to engage. As they can see, hear, and understand the concepts from the start, they relate the task, the skills, and the learning to other everyday settings, and can imagine themselves accomplishing these things. Direct experience, as outlined here, can be a valuable tool to help people realise learning and skills they otherwise though were unapproachable.

\section{References}

1. Bandura, A. (1977), "Self-Efficacy: Toward a unifying theory of behavioral change", Psychological Review, Vol. 84, No. 2, pp.191-215. https://doi.org/10.1037/0033-295X.84.2.191

2. Bembenutty, H., Kitsantas, A. and Cleary, T.J. (Eds.)(2013), Applications of selfregulated learning across diverse disciplines: A tribute to Barry J. Zimmerman. North Carolina: IAP.

3. Blaschke, L.M., (2012), "Heutagogy and lifelong learning: A review of heutagogical practice and self-determined learning", The International Review of Research in Open and Distributed Learning, Vol. 13, No. 1, pp.56-71. https://doi.org/10.19173/irrodl.v13i1.1076

International Journal of Management and Applied Research, 2020, Vol. 7, No. 3 
4. Caraway, K., Tucker, C.M., Reinke, W.M. and Hall, C. (2003), "Self-efficacy, goal orientation, and fear of failure as predictors of school engagement in high school students", Psychology in the Schools, Vol. 40, No. 4, pp.417-427. https://doi.org/10.1002/pits.10092

5. Cervone, D. (2000), "Thinking about self-efficacy", Behavior modification, Vol. 24, No. 1, pp.30-56. https://doi.org/10.1177/0145445500241002

6. Clark, J. M. and Paivio, A. (1991), "Dual coding theory and education", Educational Psychology Review, Vol. 3, No. 3, pp. 149-210. https://doi.org/10.1007/BF01320076

7. Halverson, R. (2005), "What can K-12 school leaders learn from video games and gaming?", Innovate: journal of online education, Vol. 1, No. 6, Article 3, pp. 1-9.

8. Hunicke, R., LeBlanc, M. and Zubek, R. (2004), "MDA: A formal approach to game design and game research", In: Proceedings of the Challenges in Games AI Workshop, Nineteenth National Conference of Artificial Intelligence, pp.1-5.

9. James, A. (2013), "Lego Serious Play: a three-dimensional approach to learning development", Journal of Learning Development in Higher Education, Vol. 6, pp. $1-18$.

10. James, A. and Nerantzi, C. (2018), "Guest Editors: A Potpourri Of Innovative Applications Of LEGO ${ }^{\circledR}$ In Learning, Teaching And Development", International Journal of Management and Applied Research, Vol. 5, No. 4, pp. 153-156. https://doi.org/10.18646/2056.54.18-011

11. James, W. (1912), Essays in Radical Empiricism. New York: Longmans, Green.

12. Jewitt, C., Bezemer, J. and O'Halloran, K. (2016), Introducing multimodality. London: Routledge.

13. Kraiger, K., Ford, J.K.and Salas, E. (1993), "Application of cognitive, skill-based, and affective theories of learning outcomes to new methods of training evaluation", Journal of applied psychology, Vol. 78, No. 2, pp. 311. https://doi.org/10.1037/0021-9010.78.2.311

14. Miksza, P. (2012), "The development of a measure of self-regulated practice behavior for beginning and intermediate instrumental music students", Journal of Research in Music Education, Vol. 59, No. 4, pp.321-338. https://doi.org/10.1177/0022429411414717

15. Nerantzi, C. and James, A. (2019), LEGO® for University Learning: Inspiring academic practice in higher education. https://doi.org/10.5281/zenodo.2813448

International Journal of Management and Applied Research, 2020, Vol. 7, No. 3 
16. Parry, C. W. (2004), "Managing the physical demands of musical performance". In: Williamon, A. (Ed.), Musical excellence: Strategies and techniques to enhance performance, London: University Press, pp.41-60.

17. Ritchie, L. (2015), Fostering self-efficacy in higher education students. London: Macmillan International Higher Education.

18. Roberts, D. (2017), "David Roberts: Why academia is still resistant to the power of imagery in learning", Research Blog from the School of Business and Economics, Loughborough University, [Online] available from: https://blog.lboro.ac.uk/sbe/2017/09/14/resisting-the-visual/ [accessed on 19 July, 2020].

19. Roos, J. and Victor, B. (2018), "How It All Began: The Origins Of LEGO ${ }^{\circledR}$ Serious Play ${ }^{\circledR}$, International Journal of Management and Applied Research, Vol. 5, No. 4, pp. 326-343. https://doi.org/10.18646/2056.54.18-025

20. Schunk, D. H. (1989), "Self-efficacy and achievement behaviors", Educational Psychology Review, Vol. 1, No. 3, pp. 173-208. https://doi.org/10.1007/BF01320134

21. Shreve, J. (2005), "Let the games begin", Edutopia. [Online] Available from: https://www.edutopia.org/video-games-classroom [accessed on 19 July 2020].

22. Snowling, M. J. and Hulme, C. E. (2005), The science of reading: A handbook. London: Blackwell Publishing. https://doi.org/10.1002/9780470757642

23. Swanwick, K. (1999), Teaching music musically. London: Routledge.

24. Winn, B.M. (2009), "The design, play, and experience framework”, In: Ferdig, R. E. (Ed.), Handbook of research on effective electronic gaming in education, New York: IGI Global. pp.1010-1024. https://doi.org/ 10.4018/978-1-59904-808$6 . \operatorname{ch} 058$

25. Wittgenstein, L. (1967). Zettel, G. E. M. Anscombe and G. H. von Wright (Eds), Translated by G. E. M. Anscombe. Oxford: Blackwell.

26. Zimmerman, B.J. (2000), "Self-efficacy: An essential motive to learn", Contemporary educational psychology, Vol. 25, No. 1, pp.82-91. https://doi.org/10.1006/ceps.1999.1016 